Abstracta Iranica Abstracta Iranica

Revue bibliographique pour le domaine irano-aryen

Volume 29 | 2008

Comptes rendus des publications de 2006

\title{
Ā'ìn-e qalandarān. Kermān, Dānešgāh-e Šahīd Bāhonar, 1384/2005, 437 p., index et bibliographie.
}

\section{Mojan Membrado}

\section{(2) OpenEdition}

1 Journals

\section{Édition électronique}

URL : http://journals.openedition.org/abstractairanica/30382

DOI : 10.4000/abstractairanica.30382

ISSN : 1961-960X

Éditeur :

CNRS (UMR 7528 Mondes iraniens et indiens), Éditions de l'IFRI

\section{Édition imprimée}

Date de publication : 15 mai 2008

ISSN : 0240-8910

\section{Référence électronique}

Mojan Membrado, « Āîn-e qalandarān. Kermān, Dānešgāh-e Šahīd Bāhonar, 1384/2005, 437 p., index et bibliographie. », Abstracta Iranica [En ligne], Volume 29 | 2008, document 291, mis en ligne le 15

septembre 2008, consulté le 26 septembre 2020. URL : http://journals.openedition.org/ abstractairanica/30382 ; DOI : https://doi.org/10.4000/abstractairanica.30382

Ce document a été généré automatiquement le 26 septembre 2020.

Tous droits réservés 


\title{
A'ìn-e qalandarān. Kermān, Dānešgāh-e Šahīd Bāhonar, 1384/2005, 437 p., index et bibliographie.
}

\author{
Mojan Membrado
}

1 Ce livre tente d'évoquer (en 9 chapitres, le ch. 10 contenant des index) les différents aspects de la vie et de la voie des qalandars; principalement à travers des extraits d'œuvres littéraires et de traités mystiques. Les informations historiques sur les qalandars sont rares et quand elles existent (extraits des récits de voyages et d'ouvrages historiques) elles sont de parti-pris.

2 Après avoir passé en revue les différentes étymologies du mot qalandar (pp. 11-26), celle retenue par l'A. est la suivante : salandar devenu kalandar puis qalandar signifie « celui qui n'a pas de demeure fixe (āvāre, bì-Hānemān) ». D'après T. Yazici (voir ses articles « Kalandar » et « Ḳalandariyya » in Encyclopédie de l'Islam), ce terme apparaît pour la première fois dans un robā' ${ }^{\dagger}$ de Bābā Ṭāher 'Oryānī et dans un bref traité intitulé Kalandar-nāme du célébre 'Abd Allāh Anșārī (m. 481/1088-9). Il dériverait du persan kalandar ou kalāntar. C'est le nom donné aux membres d'une classe de derviches qui existaient autrefois, surtout aux $\mathrm{VII}^{\mathrm{e}} / \mathrm{XIII}^{\mathrm{e}} \mathrm{s}$., au sein du monde musulman et se distinguaient des autres Musulmans par leur adhésion à la doctrine des Malāmatiyye ainsi que par leur habillement, leur comportement et leur mode de vie non conformistes.

Dans ce livre le terme qalandar désigne tantôt un mystique détaché du monde, tantôt un groupe organisé avec des objectifs égalitaristes. L'A. parle en effet de la branche armée de $\bar{a}$ ’’n-e 'ešq sans toutefois définir la nature et l'histoire de ce mouvement religieux. Il affirme que les qalandars, malgré leurs apparences désorganisées et non centralisées, constituaient un ordre militaire (leurs armes et outils sont répertoriés au ch. 4) souterrain et mobile; ils initiaient à leur cause ceux qu'ils jugeaient aptes à l'être. Animés par des aspirations égalitaires ils combattaient les injustices. Ils possédaient 
leur propre langage et signes secrets. Les affirmations de l'A. sur ces caractéristiques ne sont pas précédées d'une démonstration contradictoire, ni appuyées de références.

D'un point de vue historique, d'après les études plus précises (voir Yazici op. cit. et ses références), qalandariyya était le nom donné auparavant à un mouvement qui sans être strictement organisé apparut au $\mathrm{III}^{\mathrm{e}} / \mathrm{IX}^{\mathrm{e}} \mathrm{s}$., après l'apparition de la Malāmatiyye. Au $\mathrm{VII} / \mathrm{XIII}$ s., l'ordre de Qalandariyye est formé (voir Karamustafa 2006, p. 55). Il se présente comme fortement influencé par le Bouddhisme.

5 L'A. qualifie la voie des qalandars comme un mode de vie simple et une attitude non dogmatique par rapport à la religion. Il établit des liens (flous et non développés) entre la foi des qalandars et le mithraïsme (p. 147). De même il mentionne le nom des Huāksārs (p. 153) et des 'ayyārs (p. 205) sans toutefois donner de précisions sur la nature de ces liens. Il souligne fortement l'opposition qalandar/șūfi et celle qalandar/zāhed (ch. 5).

Le ch. 10 contient l'index des mots et des noms propres. Dans la bibliographie, les ouvrages en langues européennes (cités rarement dans le texte) n'apparaissent pas. Les citations bibliographiques dans le texte comportent parfois des erreurs (p. 13, Ivanov : The Truth-worshippers).

7 Ce livre constitue une bonne référence sur les expressions et lexiques associés aux qalandars. Néanmoins sa lecture doit être complétée par celle d'autres travaux offrant une perspective historique et un regard critique. A. Karamustafa dans son "God's Unruly Friends " paru en 1994 et réédité en 2006, décrit d'une manière détaillée et documentée l'émergence et l'évolution de différents groupes de derviches ayant cette forme particulière de piété en terre d'islam. Plus récemment, la thèse de doctorat de Ch. Tortel "Saints ou Démons ? Les qalandars jalâli et autres derviches errants en Terre d'Islam (Russie méridionale et Inde) aux XIII ${ }^{e}$-XVII ${ }^{e}$ siècles à travers des textes inédits traduits du persan » soutenue à l'EPHE, de Paris en 1999, traite du même sujet.

\section{INDEX}

Thèmes : 8 . Soufisme

\section{AUTEURS}

MOJAN MEMBRADO

INaLCO - Paris 